\title{
La promoción turística por medios digitales.
} (c) (i)

\section{The tourist promotion by digital means.}

Efraín Velasteguí López. ${ }^{1}$, Salazar Andrade Diana. ${ }^{2}$, Núñez Muñoz José. ${ }^{3}$ Ulices Eduardo Barragán $^{4}$

Recibido: 13-03-2017 / Revisado: 07-05-2017 Aceptado: 05-06-2018/ Publicado: 01-07-2018

\begin{abstract}
.
DOI: https://doi.org/10.33262/cienciadigital.v2i3.197
\end{abstract}

The tourist promotion in Ecuador and the canton of La Maná should be adapted to the constant changes and technological advances, the various advantages existing in the different technological resources can be exploited for the benefit of advertising marketing of tourism, tourists nowadays spend many hours connected to the internet, this reflects the trend that more and more users and companies use this medium to obtain information worldwide.

It is necessary for tourists to obtain information, experiential of the different tourist places that can be visited, in this way the digital media have become a key factor, causing dizzying changes when choosing the place of your vacation or spend an end of a week with family and friends enjoying the wonders of tourism.

Without a doubt, traveling is one of the most enriching activities, and in La Maná there are different natural and cultural attractions that are visited by tourists who are fascinated mainly by the impressive waterfalls and rivers that show the richness of the water. One of the most used sites and promoted by Lamanenses through digital tools are the Zapanal waterfalls for their access and proximity to the town.

The use of the internet and the entire digital resource, such as social networks, mobile devices, among others, have generated changes when choosing the place of your future vacations.

\footnotetext{
${ }^{1}$ Universidad Técnica de Cotopaxi Ext. La Maná, Latacunga, Ecuador, luis.velastegui7838@utc.edu.ec

${ }^{2}$ Universidad Técnica de Cotopaxi Ext. La Maná, Latacunga, Ecuador, diana.salazar@utc.edu.ec

${ }^{3}$ Universidad Técnica de Cotopaxi Ext. La Maná, Latacunga, Ecuador, nuñez.jose@utc.edu.ec

${ }^{4}$ Universidad Estatal de Bolívar, Bolívar, Ecuador, drector@ueb.edu.ec
} 
In this investigation, surveys were established to the providers of tourist services in the La Maná county, in which they indicate in $80 \%$ that it is very important to generate policies for the tourist promotion of the canton, for this avant-garde means.

Keywords: Tourism, Information, Internet, Marketing.

\section{Resumen.}

La promoción turística en el Ecuador y en el cantón La Maná debe ser adecuada a los constantes cambios y avances tecnológicos, las diversas ventajas existentes en los diferentes recursos tecnológicos puedan ser explotados en beneficio del marketing publicitario del turismo, los turistas hoy en día pasan muchas horas conectados al internet, esto refleja la tendencia de que cada vez más usuarios y empresas utilizan este medio para obtener información a nivel mundial.

Es necesario para los turistas obtener información, vivencial de los distintos lugares turísticos que se pueden visitar, de esta forma los medios digitales se han convertido como un factor clave, provocando cambios vertiginosos a la hora de escoger el lugar de sus vacaciones o pasar un fin de semana con la familia y amigos disfrutando de las maravillas turísticas.

Sin duda viajar es una de las actividades más enriquecedoras, así en el cantón La Maná hay distintos atractivos naturales y culturales que son visitados por turistas que quedan fascinados principalmente con las impresionantes caídas de agua y ríos que son muestra de la riqueza hídrica. Uno de los sitios más aprovechados y promocionados por los lamanenses a través de herramientas digitales son las cascadas del Zapanal por su acceso y cercanía a la localidad.

El uso del internet y todo el recurso digital, como las redes sociales los dispositivos móviles entre otros han generado cambios a la hora de escoger el lugar de sus futuras vacaciones.

En esta investigación se establecieron encuestas a los prestadores de servicios turísticos del cantón La Maná, en el cual indican en un $80 \%$ que es muy importante generar políticas para la promoción turística del cantón, por esto medios vanguardistas.

Palabras clave: Turismo, Información, Internet, Marketing.

\section{Introducción.}

El ecuador puede brindar la oportunidad al turista de conocer las cuatro regiones, la Amazonía, la zona andina, la costa del Pacífico y el archipiélago de Galápagos, el ecuador es Patrimonio Natural de la Humanidad. 
Existe una insuficiente promoción turística al Ecuador, el ingreso de divisas al país por turismo de enero a septiembre de 2017 ascendió a USD 1200 millones.

La actividad turística de nuestro país se encuentra en un momento crucial, la Declaratoria de los Cielos abiertos por parte del Gobierno Central es un incentivo importante para la industria turística y el transporte aéreo nacional e internacional, ya que permitirá mejorar la conectividad del país con el resto del mundo.

El Ministerio de Turismo a finales de año 2017 lanzó la "Gran Feria Turística del Ecuador" bajo el slogan "Ecuador, tu lugar en el Mundo", una de las metas más ambiciosas para el acontecer turístico nacional, concebida para motivar a los ecuatorianos a re enamorarse de las bellezas turísticas que tiene el país. Se trata de un proyecto de promoción enfocado al turismo interno, que cuenta con el respaldo tanto de instituciones públicas como de la industria turística del país (sector hotelero, líneas aéreas, transporte turístico, entre otros), que busca generar una reacción inmediata y a corto plazo para incrementar ingreso al estado ecuatorianos, para que viajen los 365 días del año. Hasta el momento ya se realizó la etapa de lanzamiento y promoción, la etapa de la venta de los programas turísticos está ajustado hasta el primer semestre del 2018 esperando obtener los réditos deseados. (Mercado Vargas, 2012)

\section{La promoción turística.}

La promoción turística según los autores Cárdenas, E. S. 2004, Ejarque, J. 2005, Gurria, M. 1991, Jimenez, F. S. 2012, Mendoza, S. 2009, Middleton, V. 2009; Porto, J. P. 2011. Permite realizar el uso de cuatro instrumentos para la información, persuasión e influencia sobre el cliente: publicidad, promoción de ventas, relaciones públicas y ventas personales y debe proporcionar a los consumidores el conocimiento de los atractivos y de la infraestructura existente diferenciando el destino de la competencia, inspirando confianza y credibilidad además de influir en la elección del destino y en el proceso de compra.

Este conjunto de actividades y acciones propagandistas a través de campañas publicitarias y de relaciones públicas, para dar a conocer un producto o servicio turístico en el mercado La promoción turística, es la referencia a la difusión de un lugar como destino para los turistas. Es importante destacar que la llegada de visitantes a una ciudad o un país genera ingresos económicos para dicho lugar, por eso la importancia de la promoción.

La promoción turística es uno de los grandes pilares de la Comunicación del Marketing Integrado, la cual facilita las opciones de destino que tienen los usuarios que nunca se deciden donde pasar sus vacaciones dándoles una oferta turística. En el caso de la promoción de los destinos turísticos se identifican instrumentos de la promoción tradicional y no tradicional. 


\section{Las Técnicas Tradicionales de Promoción Turística.}

\section{La publicidad.}

Actualmente es común que en la industria turística se hable de promoción y publicidad de una forma indiscriminada, lo que evidencia una confusión entre estos dos conceptos.

\section{Los folletos.}

Son una gran fuente de información turística que incluyen contenido visual especializado y representan la descripción formal de los activos turísticos, además influyen en la formación de imágenes del destino mentales en los turistas.

\section{Promoción turística en la Maná}

El nombre del Cantón La Maná proviene de los vocablos "LANG MANA ATTI" que significa "Mina del Gran Rey", esto debido a la presencia de extensas minas de oro y otros minerales; otra teoría, indica que es un nombre de origen Tsáchila, donde MANA significa "HERMOSO, GRANDE", que se atribuye a la fertilidad y a la generosidad de su suelo y según la fe católica MANÁ significa comida, alimento, abundancia de productos, tierra fértil regalada por Dios.

Investigaciones arqueológicas han determinado la existencia de tolas, encontradas en Pucayacu, Estero Hondo, San Pablo, San Antonio, San Agustín de Manguila y zonas de influencia inmediata al Cantón La Maná, dichas tolas datan de hace 4000 años antes de Cristo.

En 1916, llegaron los primeros colonos a estos territorios, oficialmente en el año 1926, se reconoció el nombre de La Maná, en 1952 se inician los trámites pertinentes para alcanzar la Parroquialización, quedando así establecida como Parroquia del Cantón Pujilí el 22 de noviembre de 1952, a partir del 18 de julio de 1985, después de haber cumplido con los requisitos de ley se determina acoger la solicitud de cantonización de La Maná, de este modo para el 19 de mayo de 1986 se reconoce a La Maná como Cantón de la Provincia de Cotopaxi. El territorio del Cantón La Maná se localiza en las estribaciones de la cordillera occidental de Los Andes, en este Cantón se presentan temperaturas de entre 23 y $25{ }^{\circ} \mathrm{C}$ y una precipitación de entre 1200 a 1500 mm anuales. Cuenta con una altitud de entre 200 a 1150 m.s.n.m. 


\section{Biodiversidad de La Mana.}

\section{Flora y fauna.}

El cantón es atravesado por la cordillera denominada Nhungañan (ramificación de la cordillera andina) que nace en los Andes, su flora se compone de bosques húmedos.

Existen especies de animales en vías de extinción como: oso de anteojos (Tremarctos ornatus), jaguares, tigrillos, pecarís, y dos especies de roedores típicos como guanta (Cuniculus paca) y guatusa (Dasyprocta fuliginosa), entre otras especies de mamíferos, gran variedad de aves como garzas blancas, patos cuervos (grises con franja blanca en el cuello), papagayos, varias especies de loros, perdices, pavas de monte, algunas especies de aves del paraíso en las zonas húmedas, también cuenta con una rica diversidad de reptiles, destacando las serpientes como la falsa coral y la coral, la serpiente, entre otras especies venenosas y no venenosas. Peces como el Campeche (variedad de pez gato acorazado), bocachico, dama, vieja, zabalo, guanchiche, etc.

\section{Atractivos turísticos.}

Los atractivos del cantón La Maná siempre se han caracterizado por la gran variedad de lugares magníficos que atraen el interés de los turistas, es por ello que, a continuación, se detallan los diversos atractivos turísticos que posee el sector, de acuerdo a inventario de atractivos turísticos del GAD Provincial 2016.

Sitios Naturales.

\begin{tabular}{|c|c|c|c|c|}
\hline CATEGORÍA & TIPO & SUBTIPO & $\begin{array}{l}\text { NOMBRE DEL } \\
\text { ATRACTIVO }\end{array}$ & JERARQUIA \\
\hline & $\begin{array}{l}\text { Sistema de Área } \\
\text { protegida }\end{array}$ & Bosque Protector & \begin{tabular}{llr} 
Bosque & \multicolumn{2}{r}{ Protector } \\
Jardín & de & los \\
sueños & &
\end{tabular} & I \\
\hline \multirow[t]{7}{*}{ Sitios Naturales } & Ríos & Pozas Naturales & $\begin{array}{l}\text { La poza del } \\
\text { chimbilaco }\end{array}$ & I \\
\hline & Ríos & Cascada & $\begin{array}{l}\text { Cascada del } \\
\text { venado }\end{array}$ & I \\
\hline & Ríos & Cascada & $\begin{array}{ll}\text { Cascada } & \text { de } \\
\text { mármol } & \end{array}$ & I \\
\hline & Ríos & Pozas Naturales & $\begin{array}{l}\text { Pozas del recinto } \\
\text { Elvita }\end{array}$ & I \\
\hline & Ríos & Rápidos & $\begin{array}{l}\text { Rápidos del Río } \\
\text { Quindugua }\end{array}$ & I \\
\hline & Montaña & Colina & $\begin{array}{l}\text { Mirador Sagrado } \\
\text { Corazón de Jesús }\end{array}$ & I \\
\hline & Ríos & Cascada & $\begin{array}{ll}\text { Cascada } & \text { de } \\
\text { Magdalena } & \end{array}$ & I \\
\hline
\end{tabular}




\begin{tabular}{|c|c|c|c|}
\hline Ríos & Cascada & $\begin{array}{ll}\text { Cascada } & \text { el } \\
\text { Guadual } & \end{array}$ & I \\
\hline Ríos & Cascada & Cascada Brasil & I \\
\hline Ríos & Cascada & Cascada Tinieblas & I \\
\hline Ríos & Pozas Naturales & $\begin{array}{l}\text { Balneario Natural } \\
\text { La Argentina }\end{array}$ & I \\
\hline $\begin{array}{l}\text { Sistema de Área } \\
\text { protegida }\end{array}$ & Reserva Ecológica & $\begin{array}{l}\text { Ingreso a la } \\
\text { Reserva Ecológica } \\
\text { los Ilinizas }\end{array}$ & I \\
\hline
\end{tabular}

Fuente: Inventario de Recursos Turísticos y Naturales de Cotopaxi 2016

Elaborado por: autores

Manifestaciones Culturales.

\begin{tabular}{|c|c|c|c|c|}
\hline CATEGORÍA & TIPO & SUBTIPO & $\begin{array}{l}\text { NOMBRE DEL } \\
\text { ATRACTIVO }\end{array}$ & JERARQUÍA \\
\hline \multirow[t]{12}{*}{$\begin{array}{l}\text { Manifestaciones } \\
\text { Culturales }\end{array}$} & Etnográficas & Artesanías & $\begin{array}{l}\text { Artesanía de la fibra del } \\
\text { banano }\end{array}$ & I \\
\hline & Etnográficas & Arquitectura Vernácula & La casa del árbol & I \\
\hline & $\begin{array}{l}\text { Realizaciones } \\
\text { Técnicas y Científicas }\end{array}$ & $\begin{array}{l}\text { Explotaciones } \\
\text { Agropecuarias }\end{array}$ & $\begin{array}{lll}\text { Finca } & \text { Agroturística } & \text { El } \\
\text { Solaso } & & \end{array}$ & I \\
\hline & $\begin{array}{l}\text { Realizaciones } \\
\text { Técnicas Científicas }\end{array}$ & $\begin{array}{l}\text { Explotaciones } \\
\text { Agropecuarias }\end{array}$ & $\begin{array}{l}\text { Viveros Frutales injertos } \\
\text { Hawai }\end{array}$ & I \\
\hline & Etnográficas & Memoria Local & $\begin{array}{l}\text { Historia de la parroquia } \\
\text { Guasaganda }\end{array}$ & I \\
\hline & Históricas & Sitios Arqueológicos & $\begin{array}{l}\text { Proyecto Arqueológico } \\
\text { Machay }\end{array}$ & II \\
\hline & $\begin{array}{l}\text { Realizaciones } \\
\text { Técnicas Científicas }\end{array}$ & $\begin{array}{l}\text { Explotaciones } \\
\text { Agropecuarias }\end{array}$ & $\begin{array}{l}\text { Asociación de Productores } \\
\text { Agropecuarios Pucayacu }\end{array}$ & I \\
\hline & $\begin{array}{l}\text { Acontecimientos } \\
\text { Programados }\end{array}$ & Eventos Deportivos & Pista de Motocross & $\mathrm{I}$ \\
\hline & $\begin{array}{l}\text { Acontecimientos } \\
\text { Programados }\end{array}$ & Fiestas & $\begin{array}{l}\text { Festividades de carnaval de } \\
\text { La Maná }\end{array}$ & II \\
\hline & Etnográficas & Artesanías & Artesanías en Tagua & I \\
\hline & Etnográficas & Medicina Ancestral & Shamanismo & I \\
\hline & Históricas & Colecciones Particulares & $\begin{array}{l}\text { Colección de } \begin{array}{rr}\text { piezas } \\
\text { arqueológicas } \\
\text { Germán Albán }\end{array} \\
\text { del Arq. }\end{array}$ & II \\
\hline
\end{tabular}




\begin{tabular}{|c|c|c|}
\hline Históricas & Minas Antiguas & $\begin{array}{l}\text { Minas de oro artesanal "El } \\
\text { cañaveral" }\end{array}$ \\
\hline $\begin{array}{l}\text { Realizaciones } \\
\text { Técnicas Científicas }\end{array}$ & Explotaciones Industriales & Envasadora Agua Splendor \\
\hline $\begin{array}{l}\text { Realizaciones } \\
\text { Técnicas y Científicas }\end{array}$ & Obras Técnicas & Parque Lineal La Pista \\
\hline Etnográficas & Comidas y Bebidas Típicas & Gastronomía de Pucayacu \\
\hline Etnográficas & Ferias y Mercados & $\begin{array}{l}\text { Feria Tradicional de la } \\
\text { parroquia Pucayacu }\end{array}$ \\
\hline Históricas & Sitios Arqueológicos & Tolas de solonso \\
\hline $\begin{array}{l}\text { Realizaciones } \\
\text { Técnicas y Científicas }\end{array}$ & $\begin{array}{l}\text { Explotaciones } \\
\text { Agropecuarias }\end{array}$ & $\begin{array}{l}\text { Molienda Tradicional de } \\
\text { caña }\end{array}$ \\
\hline Realizaciones & Explotaciones & procesadora \\
\hline Técnicas y Científicas & Agropecuarias & lácteos \\
\hline $\begin{array}{l}\text { Realizaciones } \\
\text { Técnicas y Científicas }\end{array}$ & Obras Técnicas & $\begin{array}{l}\text { Puentes colgantes de Toni el } \\
\text { suizo }\end{array}$ \\
\hline
\end{tabular}

Fuente: Inventario de Recursos Turísticos y Naturales de Cotopaxi 2016

Elaborado por: autores

\section{Las Siete Cascadas del Zapanal.}

Se encuentran ubicadas a 40 minutos del cantón La Maná, en el cantón Pangua. Con vegetación tropical, que nos invita a recorrer el lugar en familia y amigos. Es ideal para salir de la rutina y conocer la magia que ocultan las tierras lamanences.

Las cascadas del Zapanal, son una maravilla natural, este lugar cuenta con un sendero extremo que te permite conocer una a una las cascadas, disfrutar de un baño en cada parada, y sentir la adrenalina de escalar y conocer especies de flora y fauna muy variadas.

La flora representativa de la zona está formada por árboles maderables como la teca, pachacos, laurel, fruta de pan, chonta, guarumo, guayacán, cedro, balsa y helechos arborescentes. Los árboles más altos alcanzan los 30 y hasta 50 metros.

La vegetación arbustiva se caracteriza por especies como el guadúa, paja toquilla, palmito, chilca, piperáceas, heliconias, aráceas. 


\section{Cascada San Martin.}

Posee una altura de 30 metros, un ancho superior e interior de 11 metros, desde la parte alta se deslizan dos fuertes corrientes de agua que caen a una pequeña laguna junto a la Cascada Escondidas.

En donde podrá hacer un descanso y observar la naturaleza que se encuentra a su alrededor y disfrutar de sus aguas cristalinas.

\section{Cascada Escondida.}

Recibe este nombre porque es visible únicamente cuando uno se coloca frente a ella, a tres metros de distancia.

Se forma sobre la roca y tiene una altura de 28 metros por cuya superficie se desliza rápidamente el agua, hasta llegar a una pequeña laguna, desde donde sigue el cauce del río. Un encantador lugar como se puede catalogar a estas hermosas cascadas debido a la impresionante caída de sus aguas cristalinas y frías.

\section{Cascada del Amor.}

Es un refugio para los enamorados y los novios y es la cuarta cascada. Tiene una primera caída de 8 metros y sus aguas caen en una pequeña laguna que posee una cueva formada por el agua sobre la roca.

\section{Cascada Encantada.}

Conocidas también como las Chorreras encantadas del Zapanal, Se forma en una de las Piedra grandes, es la más emocionante por su singular morfología y belleza. Tiene una extensión de 30 metros de largo.

El atractivo consiste en deslizarse sobre esta gran piedra que forma un tobogán que cae hasta en una pequeña piscina natural.

\section{Cascada de la Muerte.}

Tiene una altura de 80 metros. Su fuerte caudal de agua llega a una gran laguna desde donde sale vapor y aire. Se encuentra a pocos minutos de la cascada conocida como "Chorrera escondida", donde podrá beber agua para calmar la sed.

\section{Cascada del Tobogán de Piedra.}

Es la más emocionante de todo el complejo por su singular morfología y belleza. Tiene una extensión de 30 metros de largo y 11 de ancho. El atractivo consiste en deslizarse sobre esta gran piedra que forma un tobogán de aproximadamente 15 metros, hasta caer en una pequeña piscina natural. 


\section{Cascada de los arrepentidos.}

Es la última cascada. Tiene 4 metros de altura, se forma sobre la roca y su caudal se desliza por el centro. A media altura se encuentra un pequeño obstáculo que hace que el agua salte Una parte de la Reserva Ecológica "Los Illinizas" (REI) se encuentra en la parroquia Pucayacu (recintos de Sandomo, Guadual, La Argentina y Choaló) aproximadamente 4.862 de 36.500 hectáreas, estos recintos ejercen actividades principalmente de agricultura y ganadería; dentro de ésta reserva encontramos a la cascada de Choaló. Otro lugar es la Montaña y la Cascada del Oso, para llegar a estos lugares se experimenta una aventura única, son aproximadamente seis horas de caminata hacia la montaña, en éste recorrido se observa la diversidad de plantaciones que existe en el bosque primario de Los Ilinizas.

Una pequeña cueva oscura que en su interior está rodeada de murciélagos, es La Cueva de los Murciélagos, al cruzar al otro lado se encuentra un lago precioso al que se lo llama el "Manto de los Novios." Hasta el momento nadie conoce la historia de las Pirámides de Mármol que se originaron en la montaña de mármol que existe en la vía a Latacunga, las personas deben ser muy observadoras para apreciarlas pues están rodeadas de vegetación, son alrededor de tres y detrás de ellas se encuentra otra hermosa cascada.

\section{Promoción turística a través de medios digitales.}

Según los autores Kotler, M. 2011, Bowen, T. 2011, Makens, C. 2011, Madariaga, J.2011, Zamora, J.2011, Morgan \& Pritchard, 2000. La promoción turística a través de medios digitales son todas aquellas formas utilizadas para que los clientes actuales y potenciales conozcan los productos, permitiendo agudizar sus sentidos y deseos y sean estimulados a comprar. Algunos autores la definen como una actividad integrada por un conjunto de acciones e instrumentos que buscan incentivar y animar a las personas a viajar, así como estimular el crecimiento y la eficiencia de las operaciones turísticas. Si bien es cierto que existen un sin número de redes sociales en la actualidad y que las mismas se utilizan para muchos fines, el uso de estas a nivel profesional como medio de promoción se ha vuelto cada vez más común, así mismo sucede con los medios de promoción digital Sin embargo no podemos negar que al menos a uno de los anuncios hemos entrado y tal vez adquirido un producto o al menos ha despertado el interés de visitar un lugar o crear una cuenta.

Es importante señalar que la economía ha mejorado por medio del turismo, se ha posicionado una imagen positiva en los últimos años

Por estos motivos es necesaria una estrategia comunicacional donde la imagen, el video, la televisión y las nuevas tecnologías se catalogan como una herramienta masiva de difusión para la promoción de una ciudad transformada y un nuevo destino turístico preferido por los viajeros. 
La promoción turística es una rama del márquetin que se lleva manejando desde hacía mucho tiempo la cual consta de tomar cierto lugar del mundo para tatar de ofrecer sus lugares atractivos o sus muchas demás cosas. En la actualidad existen demasiadas formas de realizar esta actividad como las redes sociales o medios como televisión, radio, internet estos ayudan a que la información o la promoción turística seas más rápida que de lo que se pueda imaginar.

En la actualidad lo mejor que se pude hacer para la promoción turística, es tratar de estar lo más posible ligados al internet ya que es en la web en donde se sitúa la mayor parte de las personas y por donde la información llega más rápidamente. Estar posicionados muy bien en la web es lo esencial.

Conocer cuál es la afluencia de visitas a los medios digitales para la promoción turística del Cantón La Maná, mediante una encuesta realizada a 30 personas pertenecientes al campo turístico en este caso prestadores de servicios.

\section{Resultados.}

1. Promoción turística.

\begin{tabular}{lll}
\hline INDICADOR & FRECUENCIAS & PORCENTAJE \\
\hline SI & 24 & $80 \%$ \\
NO & 6 & $20 \%$ \\
TOTAL & $\mathbf{3 0}$ & $\mathbf{1 0 0 \%}$ \\
\hline
\end{tabular}

Fuente: Trabajo de campo

Elaborado por: Autores

\section{PROMOCIÓN TURÍSTICA LA MANÁ}

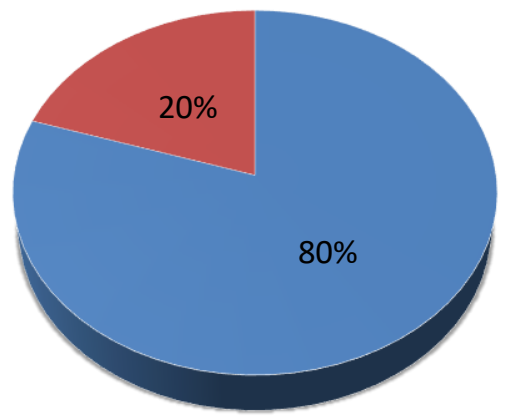

Gráfico 1: Existe Promoción turística 
Fuente: Trabajo de campo.

Nota: Datos obtenidos de los prestadores de servicios turísticos del Cantón La Maná.

\section{Interpretación:}

EL 80\% de los encuestados dicen que en el Cantón La Maná si existen lugares turísticos donde se puedan divertir los visitantes in situ, mientras que el $20 \%$ dice que no existe esta promoción turística con frecuencia mayoritariamente se la hace en feriados como los carnavales y fiestas en nuestro Cantón.

\section{Los medios digitales fomentan el turismo.}

\section{TABLA 4.}

Porcentaje de las opciones propuestas.

\begin{tabular}{ccc}
\hline OPCIONES & $\mathbf{N}^{\circ}$ & PORCENTAJE \% \\
\hline SI & 25 & $83 \%$ \\
NO & 5 & $17 \%$ \\
TOTAL & 30 & $100 \%$ \\
\hline
\end{tabular}

Nota: Cuadro del resultado realizada al personal del Municipio del Cantón La Maná.

Elaborado por: Equipo de investigación.

GRÁFICO $N^{\circ} 4$ Diagrama de representación porcentual.

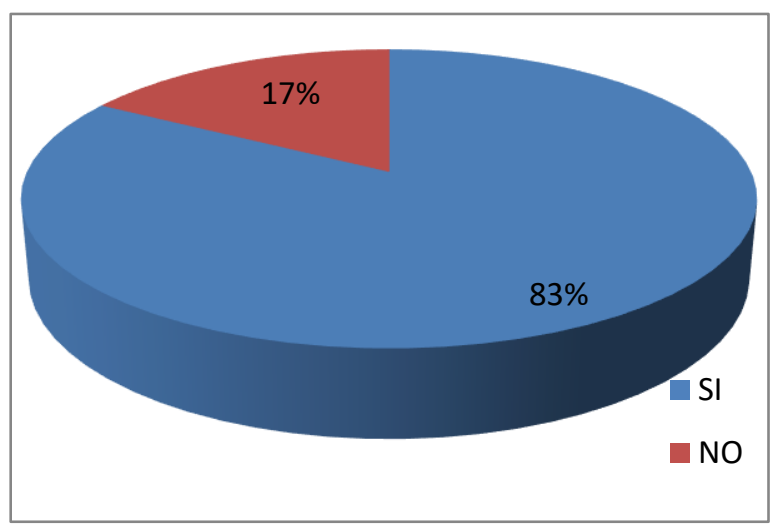


Elaborado por: Equipo de investigación.

\section{Interpretación del gráfico.}

Se observa que el $83 \%$ de las personas encuestadas dicen que los medios digitales si son una buena herramienta que nos ayuda a fomentar el turismo del cantón, ya que es muy importantes y un $17 \%$ manifiesta que no es tan importante fomentar el turismo mediante los medios digitales.

Medios digitales utilizados por el municipio son necesarios para promocionar el turismo del Cantón.

TABLA 1 Porcentaje de las opciones propuestas.

\begin{tabular}{ccc}
\hline & & PORCENTAJE \% \\
\hline SI & 25 & $83 \%$ \\
NO & 5 & $17 \%$ \\
TOTAL & 30 & $100 \%$ \\
\hline
\end{tabular}

Nota: Cuadro de la encuesta realizada al personal del Municipio del Cantón La Maná.

Elaborado por: Grupo de alumnos.

Grafico $\boldsymbol{n}^{\circ} \mathbf{1}$ diagrama de representación porcentual.

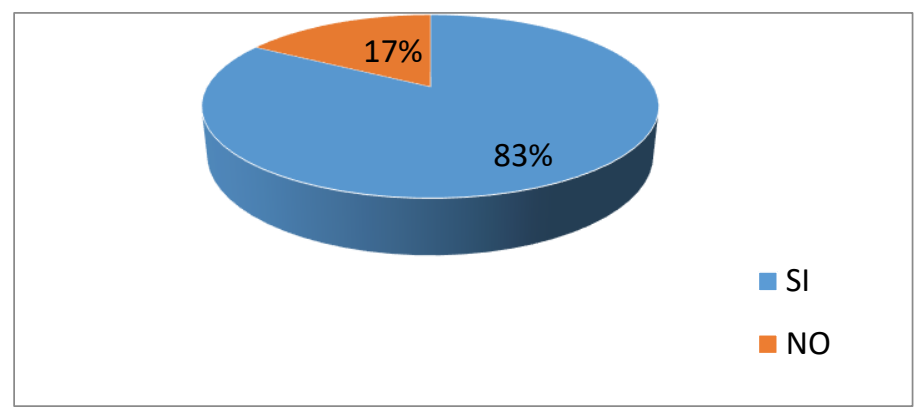

Nota: SI fue la que tuvo el mayor porcentaje con un $83 \%$ debido a que los medios digitales que proporciona el Municipio son necesarios para promover el turismo en el Cantón.

Elaborado por: Grupo de alumnos. 


\section{Interpretación del gráfico.}

Se pudo observar en la encuesta realizada que la opción SI es la que tuvo un mayor porcentaje de un $83 \%$ debido a que los medios digitales que utiliza el Municipio son los adecuados para promover el turismo del cantón, mientras que un 17\% manifestaron que aún faltan mejor los medios digitales para tener un mayor porcentaje en turistas en el Cantón.

\section{Conclusiones.}

- La promoción turística realizada por el Gobierno Autónomo Descentralizado Municipal del cantón La Maná a través de medios digitales es muy limitada, se realiza principalmente en una época del año, posiblemente por la poca o nula asignación presupuestaria para el efecto, carece en su totalidad de estrategias de marketing que permita establecer los lineamientos para potenciar el turismo en la localidad con herramientas 2.0 lo cual disminuye la eficiencia en la búsqueda de la información necesaria para el turista, para tomar las decisiones pertinentes. Se debe considerar que el impulsar el uso de medios digitales protege el ambiente; también, se reduciría los costos de promoción, al evitar afiches y demás elementos promocionales.

- Los prestadores de servicios turísticos están convencidos que el cantón tiene potencial turístico para hacer del turismo una actividad económica alternativa, para lo cual se debe implementar estrategias digitales para mejorar la relación con los clientes, que son cada vez más formados e informados en el uso de la tecnología, haciéndose necesaria la vinculación de empresas turísticas con el mercado de las TIC.

- Al estar poco definidas las estrategias de marketing, los turistas hacen uso mínimo de los servicios de alimentación, hospedaje, transporte, por el desconocimiento de estos servicios, lo cual limita el desarrollo socioeconómico y un turismo sostenible. Es emergente en el cantón cubrir la carencia de estrategias de marketing digital, que ha limitado el crear un valor agregado intangible para el cliente potencial, afectando la imagen del territorio como destino turístico.

- Incluir medios digitales en la promoción turística de la Maná permitirá una interacción con el cliente, eliminará distancias y fortalecerá distintas áreas del turismo así como la atención al cliente, relaciones públicas, publicidad, operación, marketing, ventas, servicios. Esta interacción atribuye a conocimiento de los turistas para crear nuevos productos y servicios personalizados de acuerdo a las necesidades.

\section{Bibliografía.}


Cárdenas, E. S. (2004). Promoción turística (Maria teresa Lema ed.). La Paz, Bolivia: EDOBOL. Pag, 11.

Ejarque, J. (2005). Destinos turísticos de éxito: diseño, creación, gestión y marketing. Madrid: Piramide. Pag, 758.

Gurria, M. (1991). Corrientes turisticas. Introdución al turismo. Trillas, Mexico. Pag, 98.

Jimenez, F. S. (2012). The 2.0 tourist as recipient of touristic promotion: linguistic strategies and importance of its study. Pasos, 10(4), 143. Pag, 145.

Mendoza, S. (2009). Guia, Promoción, turismo y Promción Turistica.

Middleton, V. (2009). Promocion en el turismo. Pag, 42.

Porto, J. P. (2011). Definicion.de: Definición de promoción turística. Recuperado el 12 de 06 de 2018, de Definicion.de: Definición de promoción turística : https://definicion.de/promocionturistica/

Bowen, J. T. (2011). Marketing turístico. Madrid: Pearson.

Kotler, P. (2011). Marketing turístico. Madrid: Pearson.

Madariaga, J. G. (2011). Marketing turístico. Madrid: Pearson.

Makens, J. C. (2011). James C. Makens . Madrid: Pearson.

Morgan, N., \& Pritchard, A. (2000). Advertising in Tourism and Leisure. United States: Paperback,.

Zamora, J. F. (2011). Marketing turístico. Madrid: Pearson.

Fabara Toscano, S. (1987). Trabajo inédito del señor Salvador Fabara Toscano . .

Mercado Vargas, H. \&. (2012). El Turismo y su impacto en la economía Revista de Investigación en Turismo y Desarrollo Local. Mexico.

Silva, B. (2012). La promoción turística de los recursos naturales y manifestaciones culturales. Guaranda.

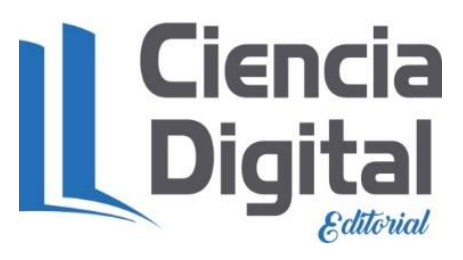




\section{Para citar el artículo indexado.}

Velasteguí E., Salazar D., Núñez J \& Barragán U. (2018). La promoción turística por medios digitales. Revista electrónica Ciencia Digital 2(3), 1-12. Recuperado desde:

http://cienciadigital.org/revistacienciadigital2/index.php/CienciaDigital/article/view/197/17 $\underline{5}$

\section{$\lfloor$ Ciencia}

El artículo que se publica es de exclusiva responsabilidad de los autores y no necesariamente reflejan el pensamiento de la Revista Ciencia Digital.

El articulo queda en propiedad de la revista y, por tanto, su publicación parcial y/o total en otro medio tiene que ser autorizado por el director de la Revista Ciencia Digital.
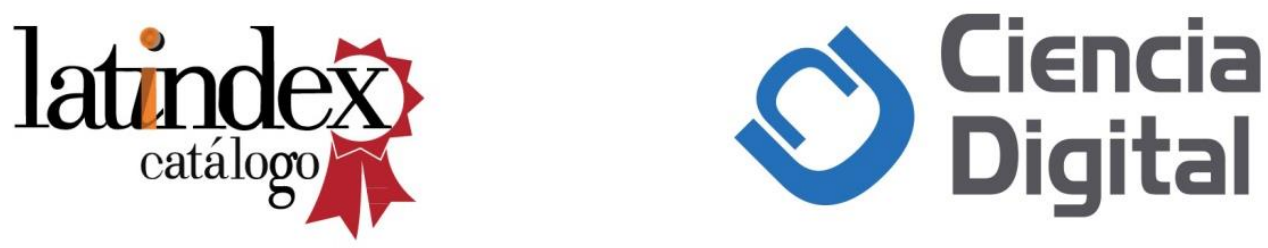